Llllie, Frank k. 

BREEDING HABITS OF THE HETERONEREIS FORM OF NEREIS LIMBATA AT WOODS HOLE. MASS.

FRANK R. LILLIE AND E. E. JUST.

- [Reprinted from Biological BulletiN, Vol. XXIV., No. 3, February, 19!3.] 4 


[Reprinted from Biological Bulletiv, Vol XXilV, No 3. Fel., igl3.]

\section{BREEDING HABITS OF THE HETERONEREIS FORM OF NEREIS LIMBATA AT IVOODS HOLE, MASS.}

FRANK R. LILLIE AND E. E. JUST.

The senior author has used the eggs of the pelagic form of Nereis limbata in studies on fertilization for several years. During the seasons of I9I I and I9I2 collections were made each night by the junior author, and records were kept which reveal considerable uniformity in swarming periods in accordance with the phases of the moon. In addition advantage was taken of the opportunity to study certain other features of breeding behavior. These observations are brought together in a paper partly for the sake of such general interest as they may possess and partly for the information of those who may have occasion to use this form for investigations.

The animals may be taken after sunset on certain nights, in general during the "dark of the moon," in the months of June, July, August and September. They appear swimming near the surface of the water very soon after sunset, and may be attracted by the light of a lantern and readily caught with a small hand net. The swarming usually begins with the appearance of a few males, readily distinguished by their bright red anterior segments and white sexual segments, darting rapidly through the water in curved paths in and out of the circle of light cast by the lantern. The much larger females then begin to appear, usually in smaller numbers, swimming laboriously through the water. Both sexes rapidly increase in numbers during the next fifteen minutes, and in the case of a large swarm there may be hundreds of males in sight at one time, though the number of females to be seen at one time rarely exceeds ten or a dozen. ${ }^{1}$ In about 45 minutes the numbers begin to decrease and

${ }^{1}$ At the height of some runs, as for instance, on the evenings of June I2, July 5 to 8, and August 6-Io, I9I2 (see curves 6,7 and I), great numbers of females. appeared. On one occasion at least a liter of females was secured in ten minutes, several being caught with each sweep of the net. Within the circle of the light on such nights as many as fifty females may be seen at once. 
in an hour, or an hour and a half, all have disappeared for the night. Next night the scene may be repeated. The females are a fresh crop each night, as will be seen from the description below, though the same males may presumably appear on several successive nights, a circumstance which, if true, will partly explain the usual great numerical preponderance of males. ${ }^{2}$

In any given night the males invariably appear first. As the females appear in increasing numbers, the males gradually grow fewer. During the first nights of a run, as well as towards the end, the males are relatively more abundant. On nights of the greatest swarms, when the females appear in great numbers, the disproportion is perhaps not as noticeable. It seems, however, that there is no definite place in the run at which this sex ratio changes, although there are some nights throughout the summer when more females than males are caught.

During the light of the moon, with exceptions noted beyond, no Nereis are to be found. They therefore occur in four periods or "runs," during the summer, corresponding to the lunar cycles in the months of June, July, August and September. Each run begins near the time of the full moon, increases to a maximum during successive nights and sinks to a low point about the time of the third quarter, then again rises and falls to extinction shortly after the new moon. Each run is therefore typically divided in two sub-runs, or the curve of nightly numbers during a run is bimodal, with a deep depression about the time of the third quarter.

When a female appears she is soon surrounded by several males, if the latter are abundant, which swim rapidly in narrow circles about her. In a little while they begin to shed sperm, rendering the water milky, and soon she begins to shed her eggs, shrinking in bulk as she does so, until, a mere shadow of her former self, she sinks slowly in the water to die. We have never succeeded in keeping females alive for more than a few days after the eggs are shed.

${ }^{2}$ The worms are eaten voraciously by certain fish, as we ascertained in I I I I when Nereis were kept in aquaria with Fundulus. During August, I9II, it was of ten noted that fish attracted by the light seemed to keep down the number of Nereis - caught. The slowly moving females were always more easily caught by the fish. This may therefore be another cause that influences the sex ratio. 
If the animals are to be kept over night for work the next day, they should be placed in separate finger bowls, preferably one for each individual, but in any case never mixing the sexes. If then the bowls are placed in a cool place, as on a water table with water flowing around them, a considerable proportion of the females and all of the males will retain their sexual products over night, and the eggs may be fertilized as desired. One great advantage of Nereis for experimental work is that each swarming individual is always fully mature, and contains no immature sexual elements whatever.

\section{The Causes of the Sperm-shedding and EgG-Sheddixg REFLEXES.}

An incidental observation of the senior author put us on the track of the immediate cause of the sperm-shedding reflex. It should be noted that males retain the sperm very tenaciously as a rule, even after days in the laboratory. One day a male was dropped accidentally in a bowl of sea water which had previously contained a female. He immediately began to shed sperm, and swam round and round in the bowl very rapidly casting sperm until the entire 200 c.c. was opalescent. This suggested that the effect of the presence of the female upon the male was exerted not through sight or touch, but through some chemical stimulus, and a few simple experiments demonstrated this conclusively.

If a ripe female be kept in a finger bowl containing about 125 c.c. of sea-water for several hours, the water will usually be found to be charged with a substance which immediately incites the sperm-shedding reflex of the male. Thus on June I7, I9II, the following test was made with about 125 c.c. of sea-water in which a female had been kept over night. A small quantity of this charged sea-water was placed in a Syracuse watch crystal, and a male was dropped in (8:15 A.M.); at once he shed sperm. Hewas then returned to fresh sea-water and ceased shedding. At 10:30 he was again dropped into a watch crystal of the charged sea-water and again shed sperm; in a few seconds he meransferred to fresh sea-water, and he ceased shedding sperm. Again at 2:07 he was transferred to another supply of the charged sea-water, and again shed sperm. Returned to fresh sea-water 
he ceased. At $2: 20$ he was tested again with positive results for the fourth time, and a little later was tested once more with water charged by another female and shed sperm once more. ${ }^{1}$

Thus each time that this animal was placed in sea-water that had contained a female for a certain length of time he responded instantaneously, and each time that he was removed and put in fresh sea-water he ceased to shed sperm.

This reaction is almost mechanical in its regularity, and can be secured with almost any male in good condition. Cases were found in which certain females apparently did not give off the effective substance, but they were very rare. As a general thing a large fully ripe female will so charge 125 c.c. of sea-water in an hour's time that any active mature male will give the spermshedding reflex almost instantaneously on being dropped in after the removal of the female, whereas even repeated transfers from one bowl of fresh sea-water to another causes no such response. If a male and female be placed together in a bowl of fresh seawater they appear to stimulate one another very quickly, but it is usually several minutes, at least in the case of animals that have been kept in the laboratory over night, before the male begins to shed sperm; and the female never sheds her eggs until after the male has begun to shed sperm.

We have seen that some kind of emanation from the female incites the male to shed sperm. In the case of the female, however, it is not any comparable emanation from the male, but the presence of sperm in the sea-water that incites the shedding of eggs. The females are much more apt to shed their eggs spontaneously than the males to shed sperm. Apparently, when fully mature, many females are unable to hold the eggs back. But, in the case of those that do, it is impossible to cause the egg-shedding reflex by putting them in water that has contained males; on the other hand, the addition of a certain quantity of

\footnotetext{
1 Mechanical shock, killing fluids, alcohol and fresh water, may cause the worms to shed their sexual products; probably any sufficiently strong shock may act similarly. But by slow addition of alcohol to the sea-water the animals may be stupefied and die extended without shedding the sexual products. Worms freshly caught react more surely to secretions of the female than those that have been in the laboratory over 18 hours. The reactions are not so definite in the late afternoon of the day after capture, and this is associated with a general lowering of tone.
} 
sperm to the water containing the fenale will usually cause shedding of the eggs.

There is thus a very precise form of sexual behavior which was tested and demonstrated repeatedly during the seasons of I9I I and I9I2. No attempt has been made to study the subject at all exhaustively as our attention was directed to other problems, but a few experiments were made dealing with the male reflex that throw some more light on the matter.

In the first place it is probable that the emanation of the female that incites the male to shed sperm comes mainly from the eggs. This could be shown in two ways: (I) Spent females, $i$.e., those that have shed their eggs, do not produce the inciting substance in quantities comparable to the production of egg-bearing females. It was possible to obtain some effects by keeping four or five spent females in a small quantity of sea-water over night; but the effect on the male was so slight as probably to be attributable to the few remaining eggs in the female, or to egg secretions persisting in their bodies. Moreover mature males would not respond to the presence of immature atokous females. (2) The eggs alone produce the inciting substance quite rapidly; thus in one experiment about one third of the eggs of a single female charged about ro c.c. of sea-water in 80 minutes so that a male shed sperm quite freely on being put in some of this water. Transferring to successive bowls of sea-water caused no reaction. The same male shed yet more freely on being transferred to the same quantity of sea-water from a bowl of 25 c.c. in which a mature female had stood over night. This was repeated with sereral variations always with positive results.

The tests showed that the eggs alone were considerably more effective than the spent females. The production of the stimulating substance should therefore be attributed mainly to the eggs.

The problem of the nature of the emanation that stimulates the males has received inadequate attention; but some experiments were made which narrow the field down considerably. In the first place the reaction is not due to the $\mathrm{CO}_{2}$ excretion of the females. This follows from the fact that males do not produce any stimulating substance, though they excrete $\mathrm{CO}_{\mathrm{s}}$. A series 
of tests was also made with various dilutions of sea-water supersaturated with $\mathrm{CO}_{2}$, all to no effect. ${ }^{1}$ In the next place it is not due to any substance common to the females of marine animals. Tests were made with sea-water charged in one case with the emanations of Fundulus, in another case with the emanations of another polychæte, Chatopterus. Males placed in portions of such charged sea-water gave no reaction whatever, but the same males placed in a portion of sea-water that had contained a female Nereis over night immediately shed sperm abundantly. The mature males of Nereis limbata will. not react even to the ripe pelagic females of a nearly related form ( $N$. megalops).

It is therefore probable that the substance in question is specific. In this there is involved no new biological principle. It is well known that the males of certain butterflies, for instance, are attracted even from long distances to the females by virtue of some air-borne emanation that is certainly specific. And the same principle must also be involved in the relations of males and females in many other instances.

Another property of the exciting substance is its lability. This is shown by its disappearance on standing in the course of about three days, and by its destruction by heat. As regards the first point, the following experiment may be noted: June 24 , I9I I. Four samples of sea-water charged by Nereis females were tested, each of which had been effective when fresh: $a$ was 7 days old, $b 5$ days, $c 3$ days, $d$ was fresh. Of these only $d$ was effective in causing male Nereis to shed sperm. Each of the samples $a$, $b$, and $c$, had been tested previously at intervals and each was found gradually to lose its stimulating power in the course of about 3 days. As regards the heat-lability of the substance in question, a series of experiments have shown that it requires about Io minutes boiling to destroy the power of an effective solution entirely. Five minutes boiling diminishes the effect considerably. The ineffectiveness after boiling is not due to the removal of oxygen, for it is impossible to restore its effectiveness by aerating.

The stimulating substance is either neutralized by the presence of sperm in the water owing to combination with some sperm

${ }^{1}$ See footnote, p. I50. 
substance, or it ceases to be effective in the presence of a certain concentration of sperm. This is shown by the following experiment, June 20, I9I I: A male put in about 8 c.c. of the water charged by a female immediately shed sperm which was stirred up by his movements; in a little while he stopped shedding. He was then transferred directly to another equal amount of the original charged water and the performance was repeated. A third transfer gave the same result, and on the fourth transfer a small amount of sperm only was shed, the male being practically spent by this time.

The same phenomenon was observed on other occasions. The explanation is, I believe, that the stimulating substance is a sperm agglutinin produced by the eggs, which enters into combination with the spermatozoa and thus disappears from the solution in the presence of a sufficient quantity of sperm. The reasons for this opinion are: (I) The sea-water charged by the female does, as a matter of fact, contain a sperm agglutinin which can be shown to be neutralized by the addition of a suffcient quantity of sperm. (2) This sperm agglutinin possesses about the same degree of heat lability as the substance effective in causing the sperm-shedding reaction of the male. The relations of the sperm to egg-secretions will form the topic of another paper, but they are summarized in a preliminary paper by the senior author in Science, N. S., Vol. XXXVI., p. 527. The conclusion to which we have come is, therefore, that the same egg-secretion of Nereis which agglutinates the spermatozoa is the effective stimulus in the sperm-shedding reflex of the male. This is the simplest explanation of the facts and may be held until some reason is shown for believing that different substances are involved: Such a condition is particularly well adapted to secure fertilization under the conditions of the breeding habits of Nereis.

\section{DATA ON THE "RUNS" AND THE "SWARMS."}

By a "run" we mean an entire lunar cycle of the pelagic "Heteronereis"; by a "swarm" the nightly occurrence. A general statement of the facts was given in the introduction. The precise data with some comparisons follow: 
I. The Swarms.-The swarms consist only of fully mature males and females; indeed we never secured even a single swarming animal which was not fully mature, or which contained any immature sexual elements mingled with the mature ones. The occurrence of swarming is dependent more upon the lunar cycle than any other factor; the relations with reference thereto are given under the second heading, "The Runs." The second most important factor in swarming is time of day; swarming begins invariably soon after twilight and continues for an hour or two at the most. A third factor is weather; very bad weather with heavy wind and rain may prevent swarming, or at least prevent the animals from coming near enough to the surface to be seen. A fourth factor is light, partially included, of course, under the second factor. But we have reference here especially to conditions that occur at the time of full moon or a little later, when swarming may begin after twilight, and be suddenly cut short by the appearance of the moon above the eastern hills. ${ }^{1}$ On the other hand during the light of the moon, i. e., from shortly after new moon until near the time of the full moon the animals do not swarm even if the moon is entirely concealed by thick clouds. ${ }^{2}$ The stage of the tide whether high or low was not an observable factor at our station, where the range of tidal movement is only about $\mathrm{I} 8$ inches. Neither do the summer variations in temperature appear to be an important factor; in any event the temperature of the water varies but little during the swarming season.

We have gained the impression that all the absolutely mature animals of any given locality swarm as soon as the right conditions are offered. This would involve the assumption that the maturing of the animals is dependent on some relation of the life history to the phases of the moon, involving probably,

${ }^{1}$ An exception to this was noted at the time of full moon in July, I9I2, when after moonrise both males and females were abundant. (See curve I, July 28 and 29.)

${ }^{2}$ As an exception it may be noted that the end of the June run (I912) extended to within three days of the full moon (see curve 6). But the general rule is as stated. Special attention was directed to this point both in IgI I and I9I2. There were several cloudy nights during the light of the moon in these years about the time of the first quarter of the moon; for instance, on July 2 I, I9I2, a hard rain fell in the afternoon and the evening was dark and cloudy, but no worms could be found. We often tried collecting in dark places under wharves, etc., on moonlit nights, but always without success. 
through lunar tidal variations, rhythmical alterations of conditions of nutrition. (Cf. Hempelmann, I9I r.) This assumption at least explains fairly well the conditions as we find them.

2. The Runs.-The collector receives very definite impression concerning the size and composition of swarms and the general features of the runs. But to give these quantitative expression is not a simple matter, though it is essential in order to reveal the order that exists. Moreover, any quantitative system of representing the data must be based on some one feature to the exclusion of others, and it is of course limited to this extent. As a result of experience we finally decided in the first place to limit the collections used in the tables to one station, and in the second place to record only females caught. The latter provision is due to the relatively enormous number of the males on certain nights which makes accurate estimation out of the question. The collecting was done each evening from the same station in the same way as nearly as possible. Practically complete records were kept for I9I I and I9I2, and these have been tabulated in the form of curves in which the ordinates represent the number of females caught and the abscissæ represent days from the first quarter of the moon.

Of these records of runs we may select that of August, 1912, as being in some respects the most typical (see curve I). It begins on the fifth day after the first quarter of the moon (July 25), and is quite atypical in this one respect, for no other run began earlier than the eighth day. On the fifth day two feamles were caught, the sixth day one, seventh day ten, eighth day eight, then the catch gradually ascends to a maximum on the twelf th day. The numbers in the successive swarms then rapidly diminish to the $1^{\text {th }}$ day, when only three females were caught, but on the I6th day there were sixteen females, and on the 17 th, I 8 th, I9th, 2oth, and 2 Ist, over thirty. The numbers then gradually decreased to the 26 th day, which was the last day of the run. This run had been preceded by eight days in which no Nereis occurred, and it was followed by a barren period of eleven days It was therefore sharply separated from preceding and succeeding runs.

The other runs may be compared with this one as follows: 
I. June, I9II; curve 2. The first collection was made on June I2, one day after the full moon or ten days after the first quarter. Judging by experience this was probably the second or third day of the run. That night 12 females were caught. The curve of this run is bimodal, sinking to zero on the 2oth day from the first quarter, and then rising again. The last swarm of the run was on the 28th day after the first quarter. There is a depression in the first mode due to some unknown cause. This run was separated from the following July run by eleven days in which neither sex could be found.

2. The July, I9I I, run (curve 3) began on the ninth day after the first quarter of the moon, thus on the night of the full moon (July II). The curve of this run is also bimodal with a deep depression from the $I 7$ th to the 2 Ist days; the last swarm was on the 26th day. Here also there is a depression in the first mode. There was an interval of eleven days from the last swarm of the July run to the first August swarm.

3. August, I9II. The run (curve 4) began on the eighth day after the first quarter and lasted to the 26th day. While the curve is decidedly irregular it is nevertheless distinctly bimodal, with a depression to zero on the I7th day. Seventeen days elapsed before the beginning of the September run.

4. September, igII. The run (curve 5) began on the thirteenth day after the first quarter. The swarms were extremely small and few in number. But parts of the two modes of the usual curve may be recognized.

5. June, I9I2; curve 6 . The first worms were secured on the I3th day after the first quarter of the moon. I regard the collections from the I 3 th to the I 7 th days as constituting the first mode of the curve. The second mode is very unusual, first in its irregularity, and second in its duration; it continued in fact ten days after the new moon, and it exceeds all other records in this respect by six days. There was thus an interval of only four days between the end of June and the beginning of the July run in 1912. The last seven days of the June run thus occurred during the "light of the moon," a circumstance which must be regarded as significant. Swarming can thus take place during moonlight. Its usual absence must therefore be inter- 
preted to mean that completely metamorphosed animals usually do not occur during this time.

6. July, I912; curve 7 . The run began on the ninth day after the first quarter of the moon, on the night of the full moon (June 29). This run shows no evidence of two modes, for the lack of animals on the second night of the run cannot be interpreted as the intermodal depression. The run continued until the 27 th day. The absence of two modes in this case may be attributed to overlapping of the two sub-runs making up each run. This run was followed by eight days without any swarms. The August, I912, run, already described, finished on the 26th day after the first quarter; and there was an interval of eleven days before the beginning of the September run.

7 . September, I9I2; curve 8 . This run began on the eighth day after the first quarter of the moon, and ended unusually early on the $23 \mathrm{~d}$ day. Though the curve is irregular in its first part there is some evidence of bimodality.

The two features that stand out most prominently in these records are the relation of the runs to the lunar cycles, and the double character of each run. The following tabulation brings out the first point; the days being numbered from the first quarter of the moon in each case:

I9I I. First run, tenth to twenty-eighth day.

Second run, ninth to twenty-sixth day.

Third run, eighth to twenty-sixth day.

Fourth run, thirteenth to twenty-first day.

19I2. First run, thirteenth to thirty-fourth day.

Second run, ninth to twenty-seventh day.

Third run, fifth to twenty-sixth day.

Fourth run, eighth to twenty-third day.

As regards the second point, the curves show sufficiently well that each run is made up of two sub-runs. But they are not usually sharply separated by an interval as in the case of the main runs; however, the general rule is that the interval occurs near the time of the third quarter of the moon. Thus the low points in the runs as tabulated are:

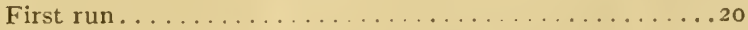

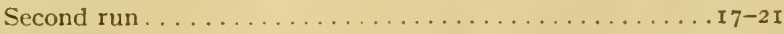

Third run . . . . . . . . . . . . . . . . . . .

Fourth $\operatorname{run} . \ldots \ldots \ldots \ldots \ldots \ldots \ldots \ldots \ldots \ldots \ldots \ldots \ldots \ldots \ldots \ldots$ 


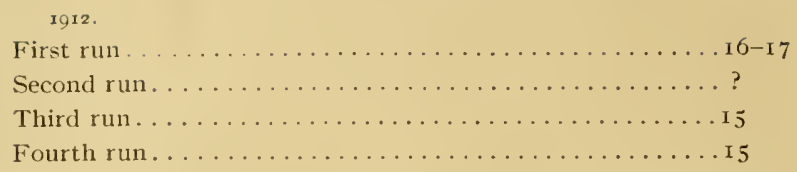

The third quarter of the moon comes $16-17$ days after the first quarter.

Hempelmann (I9II) finds that the swarms of Nereis dumerilii at Naples tend to center around the time of the first and third quarters of the moon; none were caught on the days of the new moon or the full moon. Thus, the monthly curve is bimodal as in the case of Nereis limbata, but the modes, occurring at the time of the first and third quarters, do not coincide, but alternate with those of $N$. limbata which approximate the times of the full moon and the new moon. The animals were secured from the daily plankton catch taken in the early morning hours, so little is known about the duration of the swarming or the time of its maximum. But the indications are that the time of the daily swarm is early morning (before sunrise?), and this furnishes another contrast to $N$. limbata. The runs of $N$. dumerilii occurred at Naples from October to May.

According to Akira Izuka (I903) the Japanese palolo (Ceratocephale Osawai) swarms closely following the new moon and the full moon. The swarms occur shortly after sunset and last an hour and a half to two hours. Each run is limited to three or four nights in the months of October and November. Thus there are two entirely distinct runs each month in this case corresponding to the sub-runs in the case of Nereis limbata. About ten days after each swarming period transitional halfepitokous forms are found in the bottom mud, which finish their metamorphosis in time for the next swarming period, after which only immature animals are to be found in the mud. The periodic swarming is thus dependent on periodic maturation of the animals. In many respects the swarming of Ceratocephale is more like that of the Woods Hole Nereis than any other form.

The breeding habits of the Pacific palolo (Eunice viridis), the Atlantic palolo (Eunice furcata), and Odontosyllis (Galloway and Welch, I9II), are similar with respect to periodicity dependent on lunar phases, though of course different in many details. 
Some other annelids (e.g., Amphitrite; see Scott, 1909) exhibit a lunar periodicity in breeding habits. The periodicity in Nereis limbata thus belongs to a large class of phenomena, which includes breeding seasons of some plants as well as many other animals, for which no adequate general cause has yet been found.

\section{The Life History of Nereis limbata.}

This subject is still under investigation. It is obvious that interpretation of the swarming behavior must wait for fairly complete knowledge of the life history. The present indications are that the worms either do not mature in the atokous condition, or, if they do so, that it is at an earlier time of year than our collections were made. The atokous forms were secured both in scrapings from piles of wharves and also by digging, and were kept under observation in the laboratory. All that matured underwent metamorphosis to the epitokous condition. Despite repeated efforts we failed to rear mature worms from artificially fertilized eggs. However, a few were raised to young worms about $5 \mathrm{~mm}$. in length, about eight weeks after fertilization; but all of them died after an attempted change in culture methods.

\section{LITERATURE REFERRED TO.}

\section{Friedlander, Benedict.}

'98 Ueber den sogenannten Palolowurm. Biol. C'bl., Vol. XVIII.

Galloway, T. W., and Welch, Paul S.

'II Studies on a Phosphorescent Bermudan Annelid, Odonlosyllis enopla Verrill. Trans. Am. Entomological Soc., Vol. XXX.

\section{Hempelmann, Fr.}

'I I Zur Naturgeschichte von Nereis Dumerilii Aud. et Edw. Zoölogica, Bd. 25. Lief. I (Heft 62).

\section{Izuka, Akira.}

'o3 Observations on the Japanese Palolo. Journ. Coll. Imp. Univ., Tokyo, Vol. XVII., Art. II.

Mayer, A. G.

'o2 The Atlantic Palolo. Science Bulletin, Mus. Brooklyn Acad. Arts and Sci., Vol I.

'o3 An Atlantic Palolo, Staurocephalus gregaricus.

'o7 The Annual Swarming of the Atlantic Palolo. Seventh Internat. Zoöl. Congress.

'08 Publication 102 Carnegie Inst., Washington.

Scott, John W.

'og Some Egg-laying Habits of A mphitrile ornala Verrill. Biol. Bull., Vol. X゙VIr. 
Treadwell, A. L.

'ro The Annelid Fauna of Tortugas. Year Book Carnegie Inst., Washington, Vol. VIII., p. 139 .

Woodworth, W. McM.

'o3 Preliminary Report on the Palolo Worm of Samoa, Eunice viridis Gray. Am. Nat., Vol. XxXVII.

'o7 The Palolo Worm, Eunice viridis (Gray). Bull. Mus. Comp. Zoöl., Vol. LI., No. I. 
General Description of Curies.

The ordinates represent the number of females caught.

The abscissæ represent days from the first quarter of the moon. The various phases of the moon are indicated. The days of the month are given in the second horizontal row of figures below the curves.

Curve I. The August run, IgI2.

CURVE 2. The June run, IgII. 


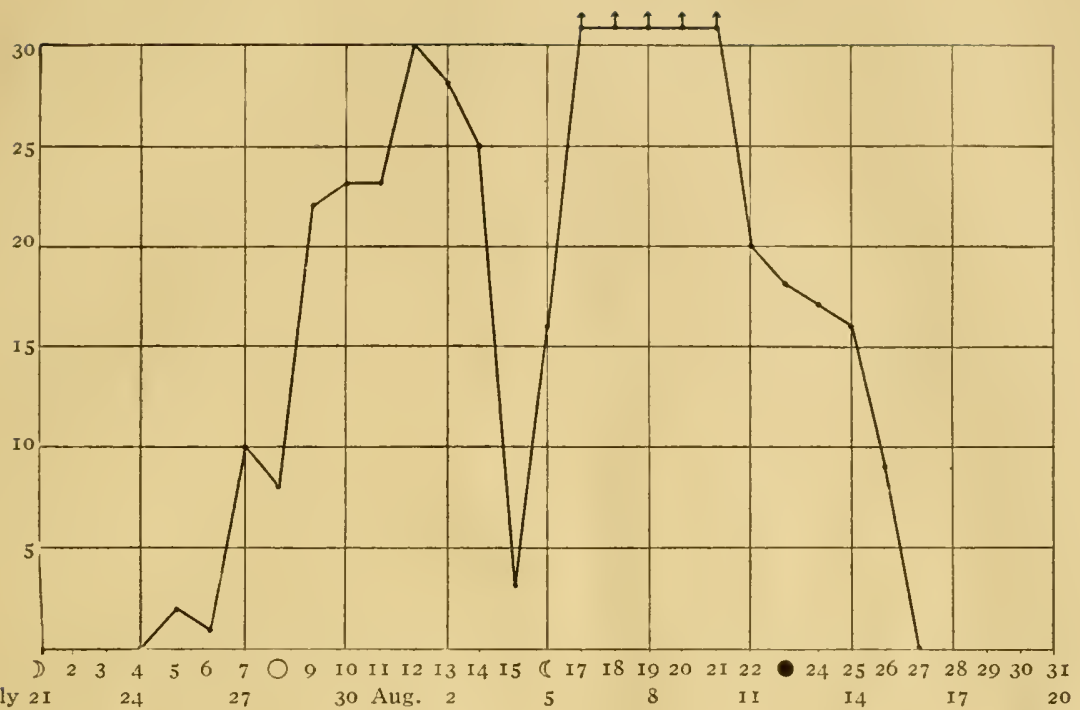

CURVE 2

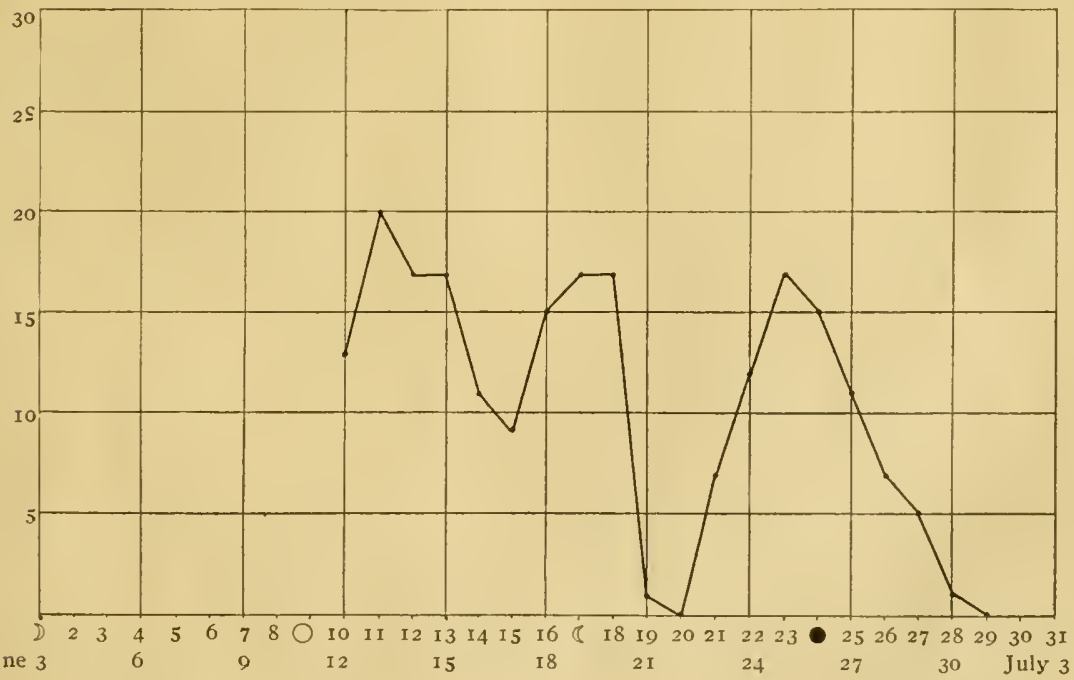

LILLIE ANO JUST 


FRANK R, LILLIE AND E, E. JUST.

Curve 3. The July run, IgII.

Curve 4. The August run, igr I. 


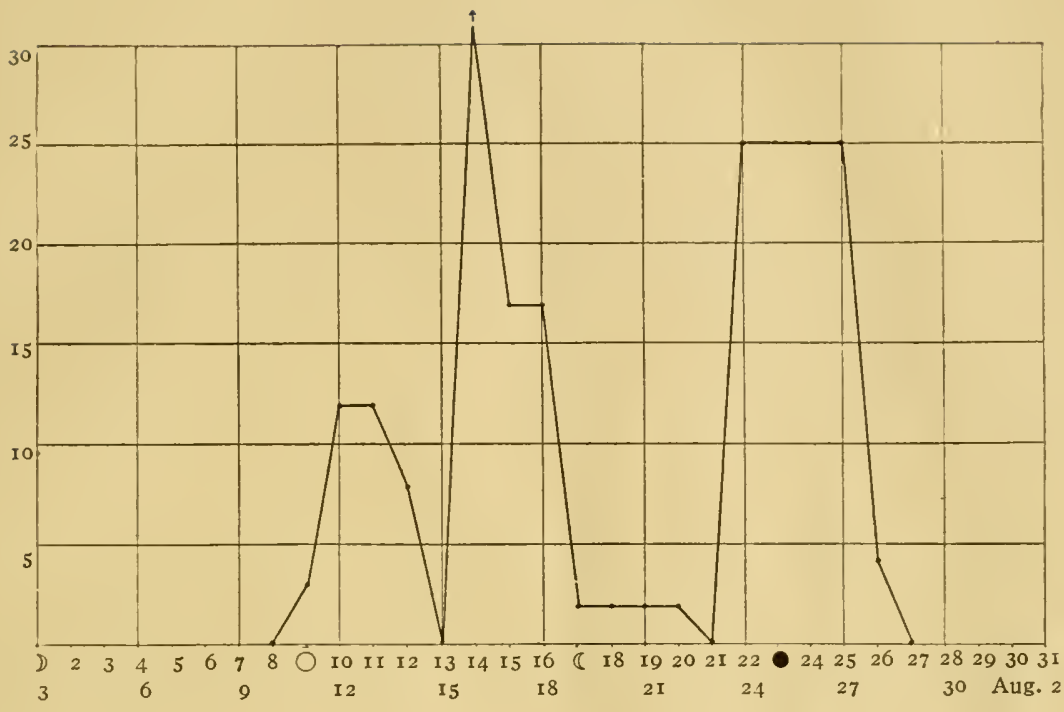

CURVE 4

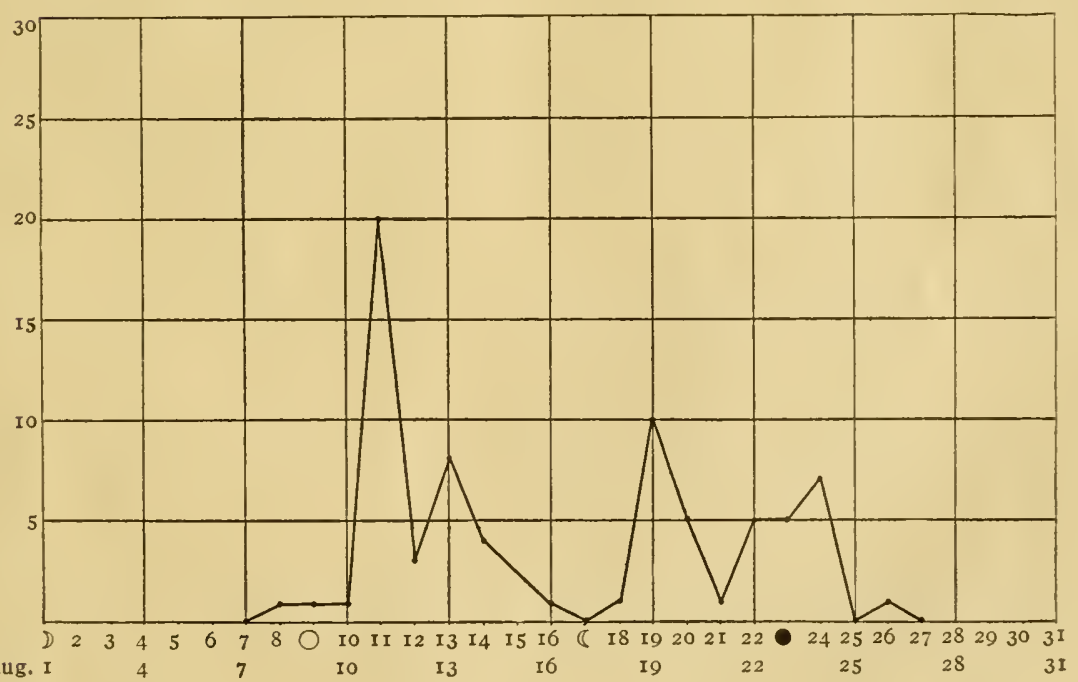

LILLIE AND JUST 


Curve 5. The September run, I9I I.

Curve 6. The June run, IgI2. The part of the curve to the left is the end of the June run as indicated by the arrow at the extreme right, and by the second : ow of dates which refer to this part of the curve (see footnote, p. I54). 


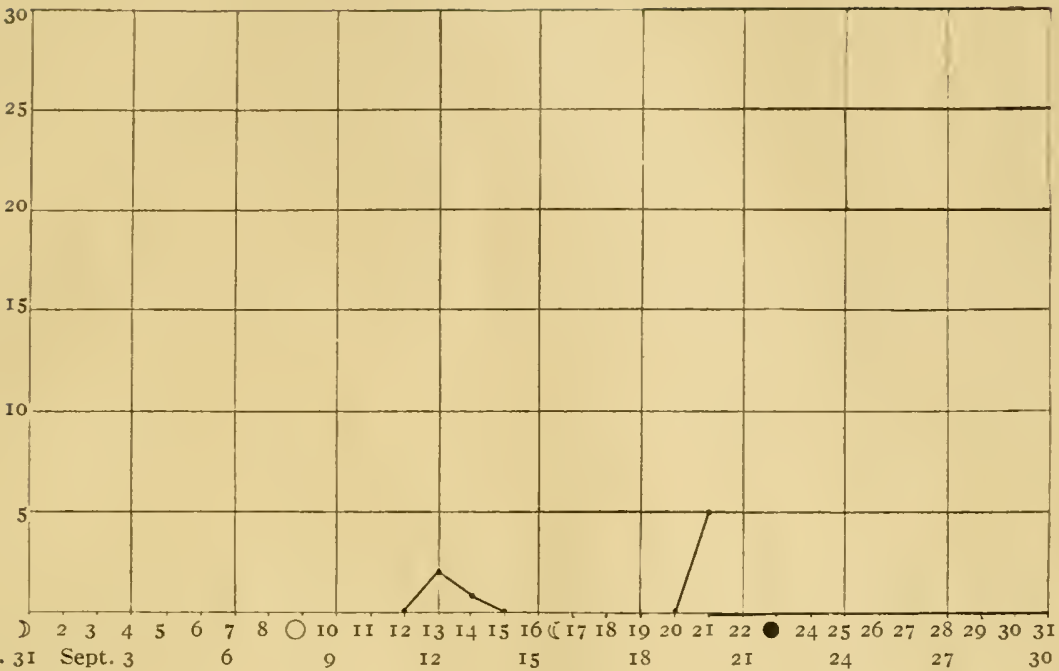

CURVE 6

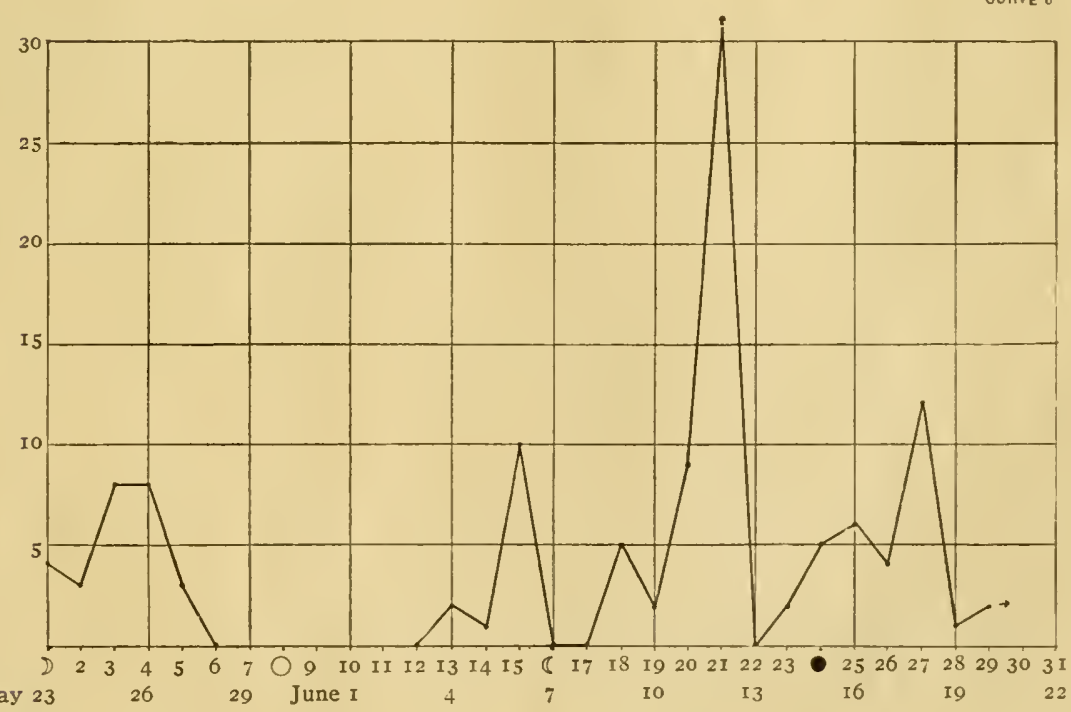

June 2 I

LILLIE ANO JUST 


CURVE 7. The July run, I9I2.

Curve 8. The September run, I9I2. 

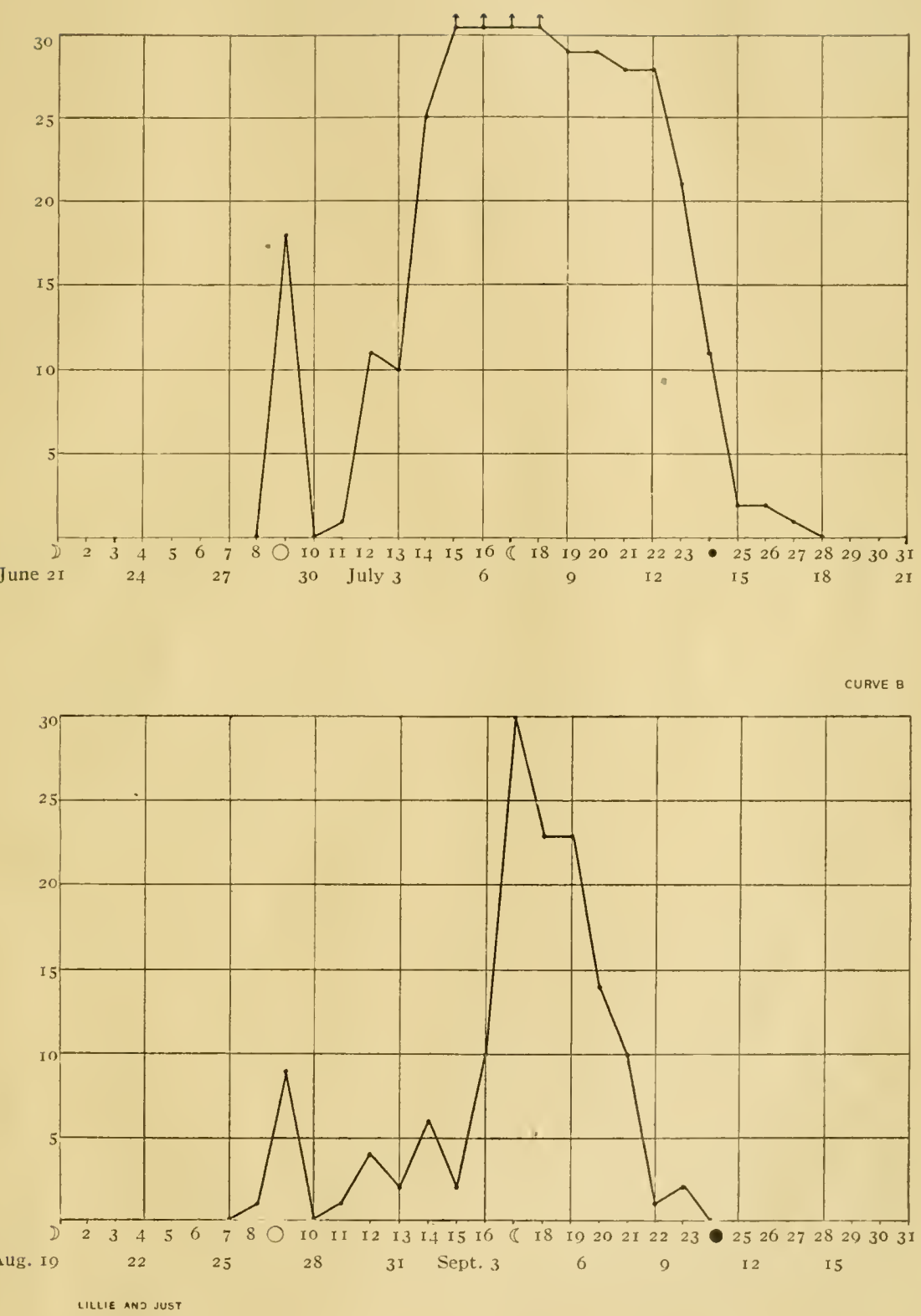



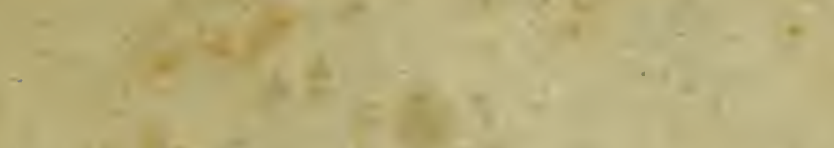

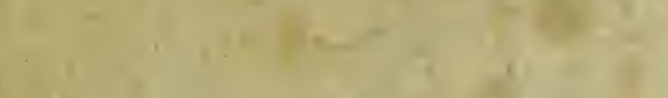

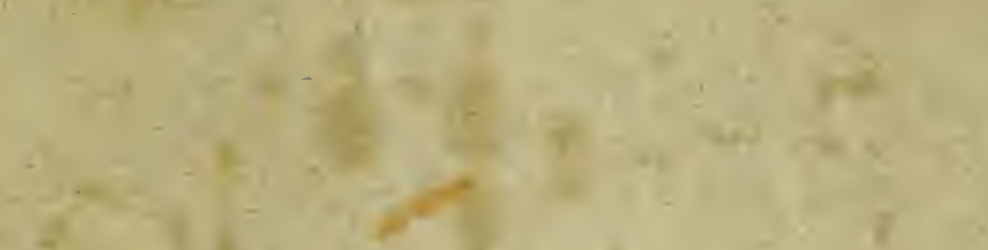

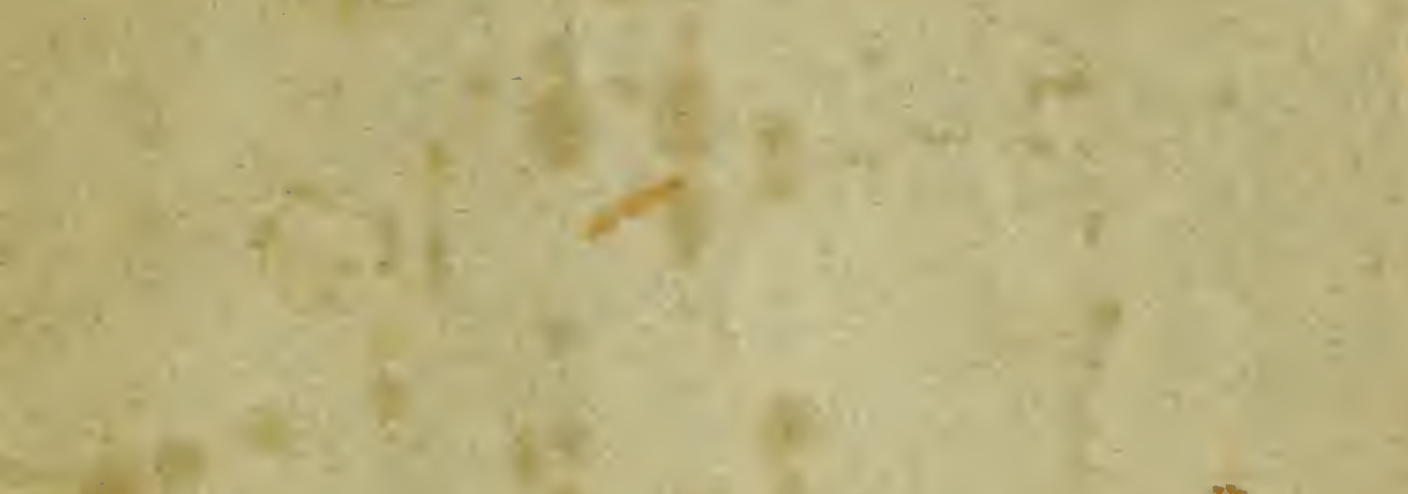

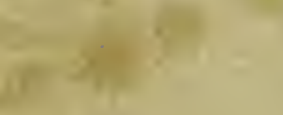
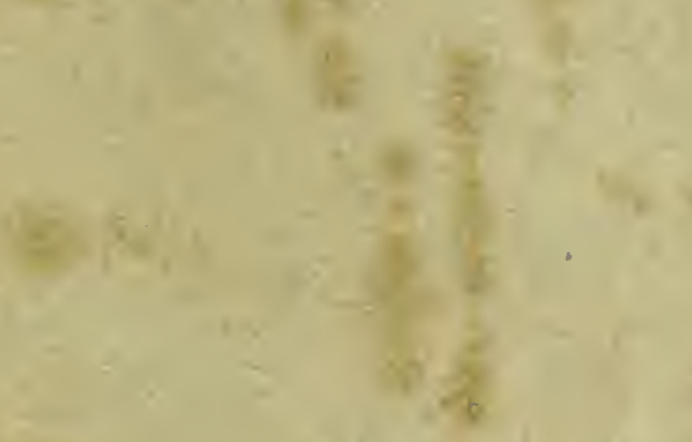

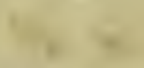

$$
14
$$

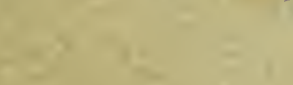

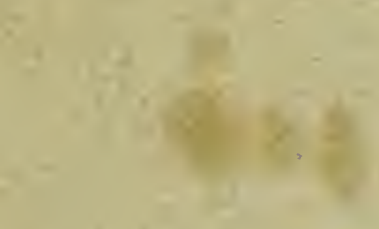

$-$

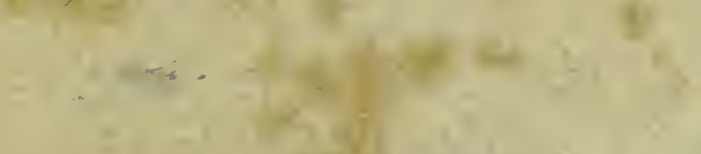

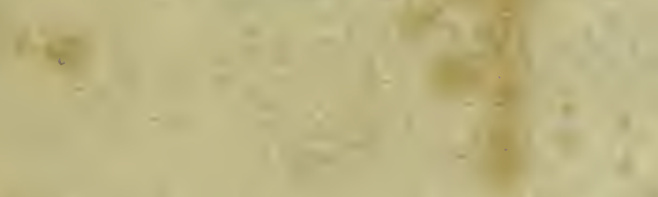

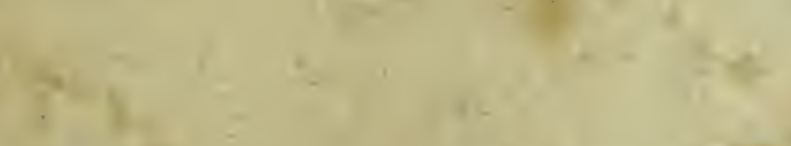<smiles>CC1CC1</smiles>

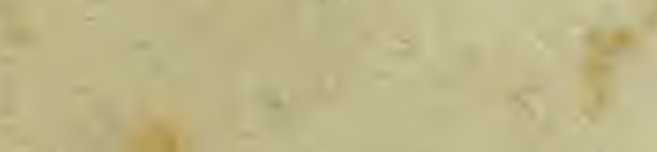




$$
\begin{aligned}
& \text { Yy }
\end{aligned}
$$

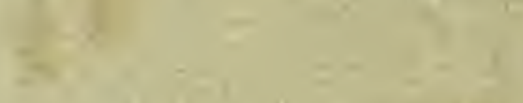

$$
\begin{aligned}
& \text { (10. } \\
& \text { for }
\end{aligned}
$$

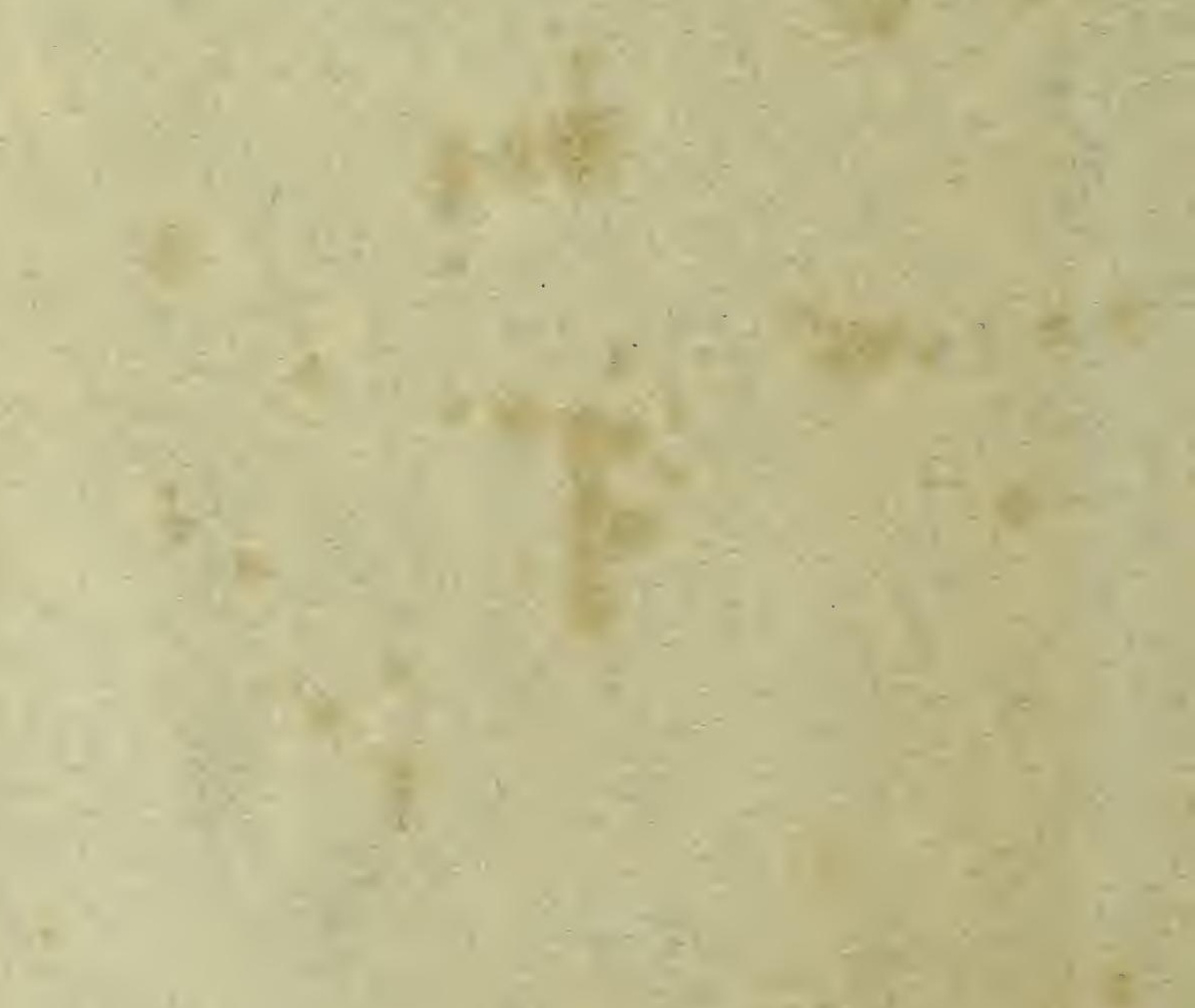

$$
\begin{aligned}
& \text { 4. } \\
& x^{1}= \\
& \text { r }
\end{aligned}
$$



